\title{
КОНЦЕПТУАЛЬНЫЕ ПОДХОДЫ В ИСТОРИИ ПЕДАГОГИЧЕСКОГО МЕНЕДЖМЕНТА ВЫСШЕЙ ШКОЛЫ
}

\author{
О. А. Косинова \\ Московский гуманитарный университет
}

\begin{abstract}
Аннотация: В настоящее время задача менеджера высшей школы формулируется очень близко к педагогическим понятиям. Она состоит в том, чтобы организовать эффективную совместную работу, в процессе которой каждый человек был бы способен максимально раскрыть свой творческий и производственный потенциал. Историографический обзор педагогического менеджмента позволяет проследить этапы и тенденции современного развития, выделить наиболее ярких авторов, их идеи, теории и концепции.
\end{abstract}

Ключевые слова: теория управления; система образования; высшее образование; педагогический менеджмент; историография; модель образования; научная школа

\section{CONCEPTUAL APPROACHES IN THE HISTORY OF HIGHER SCHOOL PEDAGOGICAL MANAGEMENT}

\author{
O. A. Kosinova
}

\section{Moscow University for the Humanities}

Аннотация: Nowadays a higher school manager's task is formulated very closely to pedagogical concepts. It consists in organising effective collaboration in which every person would be able to realise their full creative and productive potential. A historiographic review of pedagogical management makes it possible to trace the stages and trends of its modern development and distinguish the brightest authors, their ideas, theories, and concepts.

Keywords: management theory; education system; higher education; pedagogical management; historiography; education model; school of thought

\section{Вступление}

Теория менеджмента появилась как система знаний об эффективном управлении экономическими ресурсами в условиях их ограниченности. Соединившись с исследованиями о деятельности больших групп людей (социология) и закономерностями существования систем (кибернетика), теория управления вышла за пределы сугубо экономического знания приблизительно в середине XX века. В настоящее время педагогический менеджмент явля- 
Научные труды Московского гуманитарного университета 2019 № 4

ется одновременно и отраслью в системе педагогических наук, и самостоятельной областью знания. В самом общем плане предметом педагогического менеджмента является управление образованием. Специфика управления в значительной степени определяется образовательным уровнем.

\section{Категориальный аппарат и проблематика педагогического менеджмента высшего образования}

Понятие об управлении образованием пришло в отечественную педагогику вместе с идеями немецкой философии образования и педагогики, считавшейся в XVIII-XIX веках классическими для построения системы образования. Оно закрепилось в термине «школоведение», означавшем определенные правила поддержания дисциплины, а также, более широко, - целенаправленность и организованность учебно-воспитательного процесса. Усложнение системы образования обусловило развитие теории управления образованием. Категориальный аппарат отечественного педагогического менеджмента находится в настоящее время на стадии становления. По этой причине российская педагогика ориентирована преимущественно на разработку общих для всей системы образования вопросов, согласование позиций.

Определение самой отрасли, ее предмета зависит от методологического подхода. Множество предлагаемых исследовательских инструментов можно свести к двум принципиально различным подходам: структурно-функциональному подходу, заимствованному педагогикой из теории менеджмента, и теории субъект-субъектного характера взаимодействия в образовании, акцентирующей внимание на личностной обусловленности образовательного процесса. Несмотря на полярность подходов, между ними нет противоречия, так как они представляют собой разные ракурсы рассмотрения проблемы управления современным образованием.

C позиций структурно-функционального подхода педагогический менеджмент как наука управления образовательными системами и процессами - отрасль педагогики, предметом которой являются вопросы организации управления в сфере образования и в образовательно-воспитательных учреждениях. Теория педагогического менеджмента включает в себя комплекс принципов, методов, организационных форм и технологических приемов управления педагогическими системами подготовки служащих, направленными на повышение эффективности их профессиональной деятельности и развития личностных качеств (Симонов, 2009; Ситаров, 2014).

С опорой на трактовку образования как субъект-субъектного взаимодействия на первый план выступает понимание образования как системы отношений, опосредованных реализацией учебно-воспитательных задач (Ситаров, 2012). Подход базируется на так называемой новой онтологии 
субъекта, согласно которой смысл в мир привносит человек (М. Фуко, Ж. Делез). На содержание педагогического взаимодействия влияют личностные позиции, взгляды и т. п.; иерархия мотивов, качество трудовой жизни / учебной деятельности (Ю. К. Бабанский, В. Врум; А. Маслоу); «степень социальной сложности группы» (У. Кребс). Данный подход аккумулирует исследования, связанные с личностно обусловленными изменениями современного образования, прежде всего, социального заказа на образовательную услугу, а также условий ее получения. Общим для двух подходов является понятие эффективности образовательной деятельности в пределах рассматриваемой системы ее организации.

\section{Научные школы в теории управления}

Наиболее крупными научными школами в теории менеджмента признаны: концепция научного управления трудом и классическая (административная) школа (1910-1930-е гг.); школа «человеческих отношений» и поведенческих наук (1930-1950-е гг.); теория принятия решений и количественный подход (эмпирическая школа) (1950-1970-е гг.); системный и ситуационный подходы (1950-1970-е гг); школа социальных систем (1950-1970-е гг.); теория стратегий, инноваций и лидерства (1970-1990-е гг.); теория устойчивого развития и глобального «менеджмента без границ» (1980-1990-е гг.). Различные концепции и связанные с ними модели организации управления иллюстрировали усложнение управленческой теории, обусловленное привлечением в нее данных других наук, отражали различные ракурсы исследования названной проблемы.

Применительно к деятельности людей теория менеджмента была рассмотрена в трудах Ф. У. Тейлора, позднее - Г. Ганта, Л. Гилберта, Ф. Гилберта и др. Представители школы исходили из рационализации трудовых операций, функционального разделения труда, использования научных принципов управления; трудовые ресурсы рассматривались как факторы производства. Именно в рамках данной школы были сформулированы принципы управления: специализация и разделение труда, полномочия, естественность, дисциплина и справедливые санкции, единоначалие, единство действий, подчиненность личных интересов, справедливое вознаграждение работников за труд, порядок на рабочем месте, инициатива и поощрение работников. Принципы научного управления социалистическим производством были развиты в трудах А. А. Богданова, А. К. Гастева, П. М. Керженцева, В. И. Ленина и др. (Менеджмент, маркетинг ..., 2004: 128).

В рамках теории «человеческих взаимоотношений» в целом (Р. Блейк, К. Браун, Е. Гизелли, Д. Макгрегор, В. Зигерт, Л. Ланг, В. Оучи, Г. Триандис и др.) исследуются социально-психологические методы воздействия на ра- 
ботников, изучаются психологические качества и возможности индивида, а также свойства коллектива как консолидированного субъекта деятельности, включая неформальные объединения. В рамках этой теории рассматриваются вопросы потребностей, социальных установок, ценностных ориентаций личности, которые связываются с задачами создания «благоприятного социально-психологического климата», который зависит от стиля, методов управления и личности руководителя, его внимания к работникам. Предлагаемая в ней регуляция поведения работников является попыткой устранения конфликтов путем гармонизации отношений внутри отдельных групп, организации в целом.

Основное внимание в теории принятия управленческих решений (Р. М. Кантер, Р. Г. Мельор, Х. Роузен, Р. Таунсенд, П. Хейне и др.) уделено выбору рационального решения из нескольких возможных вариантов. С педагогической точки зрения существенно важно, что в рамках данной теории менеджеры ориентируются на максимальное использование творческого, интеллектуального и физического потенциала всех участников коммуникации. Благодаря разработкам теории менеджмента в данном направлении произошло научно обоснованное признание социальной ответственности менеджмента как перед обществом в целом, так и перед кругом людей, работающих в организации.

Психологической основой теории стратегий стало учение А. Маслоу о структуре человеческих потребностей и их влиянии на мотивацию трудовой деятельности личности. В рамках этой школы в качестве важнейшей основы управления была разработана теория лидерства, обосновано понятие качества трудовой жизни.

Сторонники теории устойчивого развития и глобального «менеджмента без границ» (Дж. Грейсон, Т. Питерс, Р. Уотермен и др.) исходили из необходимости обеспечения мирового баланса между социально-экономическим развитием и сохранением окружающей среды. В рамках данной теории были разработаны модели оптимального функционирования экономики, глобализации и интернационализации менеджмента.

\section{Советский период теории управления образованием: основные идеи и тенденции}

C начала XX века в отечественную педагогическую мысль проникают идеи, связанные с развитием производства и управленческим революциями, в разное время происходившими в странах Востока, Европы, Северной Америки. В отечественной историографии данная позиция была реализована в Е. Н. Медынским в книге «История педагогики в связи с экономическим развитием общества». Характеризуя состояние народного просвещения, Н. А. Кон- 
стантинов и Е. Н. Медынский назвали собственно педагогические проблемы системы российского образования: устранение сложной и запутанной системы элементарного и общего образования; обеспечение доступности начального и среднего общего образования; обновление содержания образования, создание соответствующей ему учебно-методической базы; подготовка педагогов. Решение этих задач стало элементом советской образовательной политики, нашедшей отражение в «Положении о единой трудовой школе» (1918), других нормативных документах Советской власти, а также в трудах В. И. Ленина, Н. К. Крупской, А. В. Луначарского. В совокупности данные историко-педагогические источники раскрывают различные аспекты процесса создания централизованной (полицентричной, по М. Н. Кузьмину) системы управления образованием. Таким образом советская власть сделала свой выбор с пользу жестко централизованной национальной системы образования. Тенденция к демократическому управлению образованием, обозначенная П. Ф. Каптеревым на Первом всероссийском съезде учителей в 1912 году на переход к общественному периоду в развитии педагогики и народного образования (Каптерев, 1915: 16), назревавшая в российском обществе с середины XIX века и проявившая себя в короткий период революционных преобразований XX века, не получила развития.

Документы советского периода, заслуженно признанные тенденциозными, тем не менее, являются свидетельствами своего времени и отражают характерные для него черты. Так, советские историки образования не могли обойти вниманием борьбу сторонников доминирования государства и коммунистической партии в управлении системой образования с представителями направления «свободного воспитания», показывая, таким образом, реальные обстоятельства становления отечественной образовательной традиции централизованного управления: «В условиях царской России эта теория (теория «свободного воспитания». - O. К.) была протестом против муштры, зубрежки, угнетения личности ребенка, против формализма в обучении и бюрократизма в управлении школой. Однако, наряду с этим, она идеализировала «природу» ребенка, отрицала использование положительных элементов опыт старой школы, проводила анархические установки в школьном деле: отрицание деления школы на классы, отрицание урока, отрицание программ и т. п.» (Константинов, Медынский, 1948: 13).

Другая тенденция в вопросе принципов управления образованием была представлена не только направлением «свободного воспитания», но и распространенной в 1920-1930-е годы педологией, Представители этих педагогических позиций, исследовавшие различные стороны становления личности ребенка, исходили из желательности такой организации системы образования, которая максимально учитывала бы семью как ближайшую среду 
Научные труды Московского гуманитарного университета 2019 № 4

формирования для ребенка и, следовательно, из необходимости учета разнообразия социальной реальности и гибкости в вопросах управления ею (Блонский, 1999).

Позднее, в 1930-1980-е годы в СССР вышло несколько обобщающих трудов по истории отечественного образования, где, наряду с вопросами обучения, воспитания, рассматривалась тема организации управления на различных образовательных уровнях и структурных звеньях системы образования, именуемая школоведением ввиду особой значимости средней школы (Ш. И. Ганелин, А. И. Пискунов, В. Я. Струминский, М. Ф. Шабаева и др.). Долгие годы в этой области происходило то, что Э. Д. Днепров назвал «желанием изменить школу, не меняя общество» (Днепров, 2013: 12).

\section{Модели организации образования}

Идея педагогического характера взаимодействия заложена в современном понимании образования как педагогически организованной социализации. Институциональный подход к изучению педагогического взаимодействия (Г. Б. Корнетов) обращает внимание на явление повторяющихся социальных практик, санкционируемых и поддерживаемых с помощью социальных норм (институтов) (Л. Бовье, Т. Веблен, Э. Дюркгейм, О. В. Иншаков, Б. Малиновский, Г. Спенсер, Б. С. Тернет, С. С. Фролов, С. Хилл и др.). Э. Дюркгейм писал: «Среди всех педагогических институтов, может быть, нет ни одного, который не был бы аналогом социального института, основные черты которого он воспроизводит в уменьшенном, хотя бы миниатюрном виде» (Дюркгейм, 1996: 60).

В рамках данного подхода различают понятия «педагогический институт» и «институт образования». Педагогическое взаимодействие характерно для педагогических институтов; тем самым подчеркивается специфика содержания отношений и организации деятельности, происходящая из сущности педагогической профессии. Второе ближе к понятию «социальная структура», отражает представление о назначении той или иной организации и чаще употребляется в социологии. Педагогический менеджмент, если подразумевать под ним уровень понимания цели и задач совместной деятельности, является характерной чертой педагогических институтов, выражает направленность управленческих усилий, педагогически обусловленный образ мышления и действий, отличающий данный вид социальных институтов от любых других.

Б. Малиновский считает институты легитимной изолированной единицей культуры (Малиновский, 2005: 51). В педагогических институтах складывается особая практика взаимодействия. Г. Б. Корнетов замечает, что «... основной вопрос педагогики - это вопрос о том, каким образом может и 
должно быть организовано образование, воспитание, обучение человека на основе его максимально возможного личностного вовлечения в педагогический процесс...» (Корнетов, 2017: 37)

При анализе образования с позиции теории целостного педагогического процесса следует учитывать его различные смыслы: образование как ценность, система, процесс, результат, - отражающие многообразие аспектов рассмотрения и множество функций, присущих данному явлению в представлениях современных людей (Сластенин, 1997: 169). Функциональный подход обеспечил появление на рубеже XX-XXI веков различных моделей образования: государственно-ведомственной, традиционной, развивающей, рационалистической, феноменологической, неинституциональной, образования взрослых. Каждая из них представляет собой вариант организации управления образованием. Моделирование, в целом, преследовало цель обоснования оптимальных условий для достижения различных целей образования.

В отечественной историографии данной темы педагогический менеджмент, как и менеджмент вообще, рассматривается в связи с деятельностью органов государственного и (или) муниципального управления (Ситаров, 2014: 19). Государственно-ведомственная модель предполагает большую долю администрирования образовательной деятельности. Модель выстраивается по ведомственному принципу; в ней существует четкое централизованное подчинение, обеспечивающее взаимодействие между органами управления образованием, определяющими социальный заказ, цель, задачи образования; образовательными организациями, следующими в своей деятельности за установленными нормативами; контрольно-надзорными органами, выявляющими соответствие достигнутых образовательных результатов определенным государством параметрам оценки. Модель закрепилась там, где исторически доля государственного регулирования системой образования была велика. Модель критикуется за абсолютизацию вертикального принципа управления «сверху вниз», неучет сущностного свойства образования как многофункциональной системы и, как следствие, подмену образовательных задач другими - унификации педагогического инструментария, экономии средств и т. п. (Днепров, 2011).

Традиционная модель образования описывает систематическое академическое образование, нацелена на развитие интеллектуальных умений посредством формирования системы базовых знаний, умений и навыков. Модель сформировалась в Новое время - период становления централизованных государств, формирования национального самосознания европейских народов, став с тех времен эталоном организации образования во многих странах, ориентированных на развитие человеческого капитала в условиях 
оскудения природных ресурсов. Процессы усиления государства и укрепления данной модели в практике образования когерентны, однако, в основу модели положена идея самореализации личности. Например, согласно М. Лютеру, предназначение образования заключается в том, чтобы воспитать для правления хороших, умелых работников и тем самым, способствовать прогрессу общества (Лютер, 1996: 107).

Первоначально данная модель образования базировалась на теологической трактовке человека. Однако, в условиях развития светского мышления и культуры, все большей автономии учебных заведений, в особенности, университетов, их опоры не на церковную, а на государственную структуру понимание самореализации человека все больше приобретало антропологический контекст. Я. А. Коменским в русле концепции природосообразного, специально организованного обучения был проработан вопрос управления образованием. В трактате «Законы хорошо организованной школы» (1657 г.) он отмечал целенаправленность обучения как его главное организационное свойство: «Организованным является то, начало и конец чего настолько связаны со всеми промежуточными членами, что все взаимно и в целом содействует общей цели» (А. Я. Коменский, 1996: 144). В рамках данной модели управление учебно-воспитательным процессом базируется на ресурсах образования. Например, переход на предметный метод организации учебного процесса поменял принцип оценки учебных достижений студентов с коллективного, основанного на их курсовой принадлежности, на индивидуализированный - в соответствии с количеством прослушанных курсов и сданных экзаменов каждым студентом (Отечественные университеты ... , 2005: 330).

Именно в рамках данной модели образования развивалась дискуссия о преимуществах и недостатках классической гимназии и реального училища, результатом которой стал проект гимназии «смешанного типа» Министерства народного просвещения под руководством П. Н. Игнатьева в 1916 г.

Модель развивающего обучения (В. В. Давыдов, Л. В. Занков, И. Я. Лернер, М. И. Махмутов, И. Т. Огородников, Д. Б. Эльконин и др.) предполагает организацию учебно-воспитательного процесса через кооперацию деятельности образовательных организаций разного вида и типа, которые входят в систему образования страны. Поэтому важнейшей чертой данной модели является вариативность компонентов системы образования: содержания образования, форм организации образовательного процесса, методов обучения. Будучи ограниченно обоснованной в советской педагогике на материале начальной школы, отдельных экспериментальных площадок, модель получила дальнейший импульс теоретического развития и прикладного воплощения в 1980-1990-е годы (В. Н. Дружинин, И. А. Зимняя, М. А. Холодная, А. В. Ху- 
торской и др.). К настоящему времени очевидно, что ряд принципов, прежде всего, нацеленность на развитие личности обучаемых, а также: субъект-субъектный подход к трактовке взаимодействия в образовании, преобладание теоретического материала в содержании образования, акцент на развитии интеллектуальных умений, большая доля самостоятельных работ обучающихся, в том числе, с выходом на исследовательскую и творческую деятельность и др., - могут быть реализованы на всех образовательных уровнях.

На первый взгляд, модель развивающего обучения является продолжением традиционной модели. Однако, имеется существенное отличие: развивающее обучение, возникнув первоначально как дидактические системы, вовсе не ограничивается обучением, интегрируя в себя проблематику дополнительного образования, воспитания, в том числе, семейного. Все названные процессы как бы «помогают» один другому. Педагогическое взаимодействие, таким образом, является объединяющим их понятием и, поэтому, трактуется в рамках модели развивающего обучения широко, вне конкретного образовательного уровня, вида образования или типа учебного заведения. В то время, как традиционная модель образования связывает интеллектуальное совершенствование личности именно с процессом обучения, как правило, в университете. В связи с этим, управление нацелено на создание условий для перехода от общего к профессиональному образованию - преемственности содержания образования, организационных условий обучения.

Скорее, своеобразным продолжением традиционной модели образования может выступать рационалистическая модель (П. Блум, Б. Скиннер и др.), нацеленная на актуализацию способности к адаптации личности к определенному обществу средствами образования. Характерными свойствами данной модели являются: утилитаризм, прикладной характер обучения, преимущественно воспроизводящий характер учебной деятельности обучаемых. Их общей чертой с традиционной моделью является ограниченность применения. Вместе с тем, данные модели иллюстрируют объективно существовавшую в педагогике дилемму между вниманием в личности обучающихся, обусловленным возрастанием роли психологического знания, и интересом к новым образовательным технологиям, детерминированным их совершенствованием, в том числе, техническим. В настоящее время ее отражает, например, дискуссия об онлайн-обучении, значительно перестраивающем организацию обучения.

Феноменологическая модель образования (А. Маслоу, К. Роджерс, В. А. Ситаров и др.) характеризуется гуманистической направленностью образования, для которой свойственно уважительное отношение к интересам и потребностям участников образовательного процесса, акцент на уникальности 
личности, индивидуализация обучения. Данная модель, распространение которой относят ко второй половине XX века, конечно, не является исторически новой. Скорее, переживания, связанные со Второй мировой войной, обострили ощущение ценности личности, а актуализация идеи толерантности с 1960-1970-х годов придала данной модели дополнительный импульс для реализации.

С позиций теории человеческого капитала, идей деятельностного общества (В. С. Библер, Б. С. Гершунский, Д. С. Лихачев и др.) процесс образования, связанный с самореализацией личности не столько в профессиональном, сколько в онтологическом смысле, длится на протяжении всей осмысленной жизни человека. В этом смысле под менеджментом понимают способ, манеру общения с людьми, власть и мастерство выстраивания отношений, особого рода умения и административные навыки (Ситаров, Смирнов, 2006).

Феноменологическая модель образования близка концепции непрерывного образования (модели образования взрослых), тоже получившей распространение со второй половины XX века.

На рубеже XX-XXI веков получила распространение неиституциональная модель образования (П. Гудман, Дж. Холтом и др.). Отчасти модель объединяет педагогов и организаторов образования, увлеченных техническим возможностями Интернета, в особенности, идеей дистанционной формы обучения. Однако, в более широкой трактовке данная модель означает обучение не в образовательном учреждении - в Интернете, на природе, в т. н. «открытых школах». Отчасти модель базируется на известном опыте человечества. Так, идея обучения на природе восходит к известным педагогическим традициям: Академии Платона и перипатетическому методу обучения, школам Конфуция и Лао-цзы. Модель нацелена на обоснование новых условий обучения, однако, не содержит определенности в отношении цели и других управленческих составляющих образования. С другой стороны, появление неиституциональнной модели свидетельствует о некоторой инерционности, проявляющей себя в современном институциональном образовании, прежде всего, в образовательных организациях.

\section{Дискуссия вокруг идеи университета}

Высшая школа ассоциируется организационно с университетским образованием. Вопрос об эффективном управлении высшим образованием, главным образом, касается роли университетов в современном обществе.

На уровне отдельной образовательной организации одной из важных управленческих задач признано формирование миссии - четко выраженной цели существования и деятельности образовательной организации. К ком- 
понентам миссии относятся: цель образовательной организации; особенности образовательных услуг; интересы, ожидания и ценности потребителей образовательных услуг; область и отрасль деятельности образовательной организации; отношение к окружающей среде и обществу; перспективы развития образовательной организации; качество образовательных услуг по отношению к конкурентам и др. (Менеджмент, маркетинг ..., 2004: 124).

Поэтому, прежде всего, дискутируется вопрос о миссии университетов. Так, говорится об изживании университетов как формы организации высшего образования в связи с кризисом идеи универсального образования как такового. Его замену видят в формировании двух ключевых личностных умений обучающихся: способности к рефлексии разных видов опыта; способности к упорядочению первичной информации и коммуникации (Гусаковский, 2017: 84). С опорой на антропологический проект М. К. Мамардашвили в качестве результата образования предлагается признать «...самостоятельное приобретение индивидом сознательного опыта деятельности, в принципе не выводимого из других сознательных опытов» (Мамардашвили, Пятигорский,1974: 86-87). Подчеркивается культурная миссия университета, что «... предполагает перемену основной базовой образовательной деятельности в университете с познавательной, организованной по схематизмам и тематизмам науки, на культурнотворческую, в основе которой иные образовательные стратегии, в частности - анализа ситуации и интерпретации» (Гусаковский, 2017: 85). Сущность университета как культурного центра представляется в порождении новых знаний, сфер, форм смыслов культуры, не сводимых к профессиональному образованию. Таким образом, сторонники данной идеи разводят для себя профессиональное образование и развитие личности как разнонаправленные явления, в каком-то смысле, противопоставляют их, анализируя роль современных университетов.

М. А. Лукацкий считает, что современное обсуждение данного вопроса есть своеобразное продолжение напряженной дискуссии начала XX века, когда решался вопрос о назначении и месте университетов в национальных системах образования - быть кузницей кадров или готовить интеллектуальную элиту: «Дифференциация и специализация рынка труда подталкивала университеты к смещению образовательной деятельности в сторону подготовки специалистов. Далекая же от спокойствия историческая и политическая ситуация в мире обращала университеты к рассмотрению задачи подготовки таких кадров, которые, имея колоссальный культурный и мыслительный багаж, смогли бы конструктивно повлиять на снижение напряженности в мире и обеспечить прогнозируемое будущее для граждан всего мира» (Лукацкий, 2017b: 8).

Структурные изменения на рынке труда, а также новый уровень науч- 
ных требований к выпускникам высшей школы вновь актуализировали дискуссию в начале XXI века. М. А. Лукацкий обращает внимание: «Среди дискутирующих (идею университета. - O. К.) сложились два лагеря - сторонники определения миссии университета, исходившие из насущных и перспективных потребностей рынка труда, и сторонники постулирования миссии университета, ориентирующиеся на эталоны сбалансированной культурной жизни людей, бытия, которое минимизирует угнетение людей несправедливым рыночным, властным и экономическим неравенством» (Лукацкий, 2017a: 139).

Другим вопросом, вокруг которого возникла дискуссия педагогов высшей школы, является вопрос о понимании компетентностного подхода. Данное понятие, пришедшее в педагогику из терминологии менеджмента в конце прошлого века, в настоящее время стало ключевым нормативным понятием стандартизации содержания высшего образования на всех его уровнях, критерием оценки подготовленности профессиональных кадров. Между тем, дискуссия подразумевает построение целесообразной верифицируемой модели подготовки обучающихся в системе высшего образования с учетом: квалификационных требований к профессии в части видов профессиональной деятельности, трудовых функций, обобщенных трудовых функций; соотношения профессиональных и образовательных компетенций; связи компетенций с более привычными преподавателям знаниями, умениями и навыками, и других сущностных вопросов дидактики.

\section{Новое государственное управление высшей школой за рубежом: принципы и тенденции}

На управление российским высшим образованием повлияла включенность в Болонское образовательное пространство. В странах Западной и отчасти Центральной Европы разработка проблематики менеджмента высшим образованием привела к оформлению принципов нового государственного управления высшей школой и следующим тенденциям ее реформирования:

1. Усилению автономии вузов в направлении расширения возможностей их саморегулирования, а также внедрению принципа субсидиарности - решения проблем на низшем уровне. В отличие от вузов США, где автономия понимается в финансовом смысле, для западноевропейских вузов данное понятие ассоциируется с академическими свободами, сохранением образовательных традиций, которые могут разниться от вуза к вузу. В целом, современное понятие автономии вуза включает в себя четыре аспекта: академический, кадровый, организационный, финансовый. Привлечение к менеджменту вузов сторонних заинтересованных лиц (представителей работодателей, частного 
бизнеса, экспертных сообществ) повлияло на изменение схемы управления, включающей в себя в настоящее время внешнее регулирование государственных / муниципальных органов, внешнее управление административными советами (в том числе, независимыми компаниями), управление администрацией вуза, академическое самоуправление. Смысл реформирования системы управления заключается в многоуровневом контроле качества высшего образования, обеспечивающих его ресурсов, распределении полномочий между различными субъектами деятельности, включая не работающих, но заинтересованных в развитии вуза лиц, а также устранение прямого политического контроля за вузами со стороны государственных структур. Одним из следствий стало повышение роли информационных менеджеров, консультантов студентов, библиотекарей, то есть, работников среднего звена, обеспечивающих управление академической деятельностью и решение частных образовательных задач «на местах».

2. Маркетизации деятельности университетов - сочетанию образовательной миссии с предпринимательским отношением к построению академического процесса: переходу на клиентоориентированный принцип трактовки образования; опору на понятие образовательной услуги, ее характеристики как товара; подчиненность образовательного продукта рыночным условиям существования, включение в конкурентную борьбу. В практике высшего образования Западной Европы в связи с этим появился термин «предпринимательский университет». Преподаватель наделяется функцией менеджера, ответственного за продажу своих знаний на рынке образовательных услуг с подчинением данному направлению деятельности академической и научно-исследовательской работы (Лиферов, 2009). Такой подход привел также к развитию различных форм государственно-частного партнерства с промышленными предприятиями, частными компаниями; в 75\% инициатива исходит от вузов (Железов, 2008: 34).

3. Диверсификации - расширению количества предлагаемых услуг за счет: расширения спектра специальностей / направлений подготовки, форм обучения, в том числе, дистанционного; дифференцированного многоуровневого обучения; принципиальное увеличение количества обучающихся внедрением принципов непрерывного образования, инклюзивного обучения; модульного принципа построения содержания дисциплин, программ; развития программ дополнительного образования; совершенствованием информационно-коммуникационного и технического обеспечения обучения. Большая доля решений принадлежит факультетам.

4. Гармонизации и контролю качества высшего образования - международного сотрудничества стран в образовательной сфере, сопровождающееся 
не только рамочными соглашениями, но и решением ряда прикладных вопросов интеграции в направлении выработки и закрепления общих принципов управления высшим образованием (Болонская декларация, Лиссабонская конвенция). Данная тенденция повышает степень согласованности образовательной деятельности как таковой в странах-участницах. Однако, реформа высшей школы критикуется за чрезмерный контроль, увеличение формальной отчетности (Корнетов, 2012).

\section{Заключение}

В настоящее время задача менеджера формулируется очень близко к педагогическим понятиям. Она состоит в том, чтобы организовать эффективную совместную работу, в процессе которой каждый человек был бы способен максимально раскрыть свой творческий и производственный потенциал через активизацию таких качеств, как: лидерство, инновационность мышления, конструктивный стиль руководства, позитивный стиль общения, профессиональная квалификация и культура. Сегодня ориентация на новые условия и факторы развития общества приобрела отражение в принципах современного менеджмента, именуемого «новой управленческой парадигмой». Формулировка принципов этой парадигмы убедительно указывает на возрастающую роль человека, его профессиональной компетентности, личностных качеств, а также всей организации системы взаимоотношений между людьми как именно педагогического менеджмента.

\section{СПИСОК ЛИТЕРАТУРЫ}

Блонский, П. П. (1999) Педология : кн. для преподават. и студ. высш. пед. учеб. заведений / под ред. В. А. Сластенина. М. : Гуманит. изд. центр ВЛАДОС.

Гусаковский, М. А. (2017) Кризис идеи университета // Историко-педагогическое знание в начале III тысячелетия : педагогические институции в истории человеческого общества : материалы Тринадцатой Международной научной конференции, Москва, 16 ноября 2017 г. / ред.-сост. Г. Б. Корнетов. М. : ACOУ. 200 с. С. 83-85.

Днепров, Э.Д. (2011) Новейшая политическая история российского образования : опыт и уроки. 2-е ид., доп. М. : Мариос. 472 с.

Днепров, Э. Д. (2013) Вехи образовательной политики. Избранные статьи и материалы. 1987-2012 годы / сост. Р. Ф. Усачева, Т. Н. Храпунова. Ч. 1. М. : Мариос.

Дюркгейм, Э. (1996) Социология образования : пер. с фр. М. : Интор.

Железов, Б. В. (2008) Осмысление опыта реформ управления высшим образованием в ЕС // Вестник международных организаций. № 2. С. 27-35. 
Каптерев, П. Ф. (1915) История русской педагогии. Пг. : Тип. В. Безобразова и $\mathrm{K}^{\circ} .746$ с.

Константинов, Н. А., Медынский, Е. Н. (1948) Очерки по истории советской школы РСФСР за 30 лет. М. : Государственное учебно-педагогическое издательство Министерства просвещения РСФСР.

Корнетов, Г. Б. (2012) Реформирование системы высшего образования в западноевропейских стран как результат внедрения концепции нового государственного управления // История теории и практики образования : в 2 т. / под ред. Г. Б. Корнетова. М.: АСОУ. Т. 1. Теория истории педагогики. История образования и педагогической мысли за рубежом. 244 с. С. 212-240.

Корнетов, Г. Б. (2017) Теоретический подход к изучению педагогических институций в историко-педагогическом процессе // Историко-педагогическое знание в начале III тысячелетия : педагогические институции в истории человеческого общества : материалы Тринадцатой Международной научной конференции, Москва, 16 ноября 2017 г. / ред.-сост. Г. Б. Корнетов. М. : АСОУ. 200 c. С. $13-37$.

Лиферов, А. П. (2009) Трансформация традиционной высшей школы в условиях постиндустриального общества // Вестник Рязанского государственного педагогического университета им. С. А. Есенина. № 1. С. 3-12.

Лукацкий, М. А. (2017а) Идея университета в прошлом и настоящем // Историко-педагогическое знание в начале III тысячелетия : педагогические институции в истории человеческого общества : материалы Тринадцатой Международной научной конференции, Москва, 16 ноября 2017 г. / ред.-сост. Г. Б. Корнетов. М. : АСОУ. 200 с. С. 134-139.

Лукацкий, М. А. (2017b) Идея университета и становление компетентностного подхода в высшем образовании // Подготовка педагогических кадров для системы высшего образования в условиях реализации компетентностно-ориентированных образовательных стандартов : сб. науч. трудов и метод. материалов / под ред. Л. Н. Антоновой, Г. Б. Корнетова, А. И. Салова. М. : АСОУ. 196 с. С. $5-18$.

Лютер, М. (1996) К советникам всех городов земли немецкой. О том, что им надлежит учреждать и поддерживать христианские школы // Мартин Лютер - реформатор, проповедник, педагог / сост. О. В. Курило. М. : Издательство РОУ. С. 91-118.

Малиновский, Б. (2005) Научная теория культуры : пер. с англ. 2-е изд., испр. М. : ОГИ.

Мамардашвили, М., Пятигорский, А. (1974) Символ и сознание. М. : Языки русской культуры. 